\title{
Oxygen Uptake and Mitochondrial Enzyme Activities in the Mitotic Cycle of Physarum polycephalum
}

\author{
By B. G. FORDE* AND W. SACHSENMAIER \\ Institut für Biochemie und Experimentelle Krebsforschung der Universität \\ Innsbruck, Peter-Mayrstrasse 2, A-6020 Innsbruck, Austria
}

(Received 20 February 1979)

\begin{abstract}
The rate of oxygen uptake by single macroplasmodia of Physarum polycephalum increased in two steps during each synchronous mitotic cycle. Plateaux in the respiratory pattern, of 0.22 cycles duration, occurred in mid-interphase and in the period up to and including mitosis. A fall in the rate of respiration was frequently associated with mitosis itself. This pattern of respiration continued for more than 10 mitotic cycles after inoculation and was unaffected by omission of an initial routine period of starvation. A similar stepped pattern of respiration was observed in synchronously germinating spherules during the period between outgrowth and the first mitosis. The specific activities of succinate dehydrogenase, fumarase and malate dehydrogenase remained relatively constant during the mitotic cycle, while fluctuations in cytochrome oxidase activity paralleled those in specific respiratory activity. Possible mechanisms for controlling the pattern of respiration are discussed with reference to published data on protoplasmic streaming and ATP concentrations during the mitotic cycle.
\end{abstract}

\section{INTRODUCTION}

Energy metabolism in the cell cyle is frequently monitored by measuring the development of respiratory activity in synchronous cultures. These experiments have, however, often yielded conflicting results. For example, according to different reports the rate of $\mathrm{O}_{2}$ uptake by one species of yeast, Saccharomyces cerevisiae, increases continuously (Cottrell \& Avers, 1970), discontinuously in steps (Scopes \& Williamson, 1964; Greksak \& Hanicova, 1973) or in a series of peaks (Nosoh \& Takamiya, 1962; Kuenzi \& Fiechter, 1969; Wiemken et al., 1970; Dharmalingam \& Jayaraman, 1973). This inconsistency suggests that the pattern of respiratory activity may be affected by the history of the cultures, and particularly by the different procedures used to synchronize the cells. Distortion of the cell cycle has been shown to occur even when one of the least disruptive synchronizing procedures - selecting cells of uniform age from a sucrose gradient - is employed (Mitchison, 1977). It was therefore of interest to study respiration in the mitotic cycle of Physarum polycephalum, an acellular slime mould in which nuclear division is naturally synchronous.

In addition to respiratory activity we have monitored the accumulation of a number of mitochondrial enzymes in $P$. polycephalum. Two models for the control of mitochondrial biogenesis in the cell cycle predict synchronous growth and division of the mitochondrial population within a single cytoplasm (Lloyd et al., 1971; Barath \& Küntzel, 1972). Although the available evidence suggests that replication of the organelle occurs asynchronously in P. polycephalum (Braun \& Evans, 1969; Guttes et al., 1969), it remains possible that the

* Present address, to which requests for reprints should be directed: Department of Botany, King's Buildings, Mayfield Road, Edinburgh EH9 3JH, Scotland. 
synthesis of individual mitochondrial components, especially those coded for by nuclear DNA (Schatz \& Mason, 1974), is associated with particular stages of the mitotic cycle.

\section{METHODS}

Culture conditions. Physarum polycephalum (strain $\mathrm{M}_{3} \mathrm{~b}$ ) was maintained at $24^{\circ} \mathrm{C}$ as a microplasmodial culture growing in semi-defined liquid medium on a reciprocal shaker, as described by Daniel \& Baldwin (1964). Synchronous macroplasmodial cultures were prepared by fusion of a microplasmodial suspension and were grown in Petri dishes at $26^{\circ} \mathrm{C}$ on filter paper or membrane filter supplied with semi-defined medium (Daniel \& Baldwin, 1964; Sachsenmaier, 1964).

Spherules were obtained and prepared for synchronous germination according to J. Mohberg (personal communication). A microplasmodial culture, inoculated at low density, was grown for 7 to $10 \mathrm{~d}$ into stationary phase, when spherules developed and formed a 'collar' on the glass above the medium. The medium, containing most of the slime, was decanted and the spherules were washed off with sterile distilled water. The spherules were sedimented at $500 \mathrm{~g}$ for $2 \mathrm{~min}$ and washed three more times with sterile distilled water. The final pellet was suspended in 2 vol. water and 0.1 to $0.2 \mathrm{ml}$ was inoculated as a thin disc on dry filter paper which rested on glass beads in a Petri dish. Growth medium, diluted with 2 vol. water, was pipetted underneath the filter paper and the spherules were incubated in darkness at $26^{\circ} \mathrm{C}$. Synchronous germination normally followed within $9 \mathrm{~h}$.

Measurement of respiration rate. The rate of $\mathrm{O}_{2}$ uptake was measured manometrically at $26^{\circ} \mathrm{C}$ in the dark. To monitor respiratory activity in a whole surface culture for up to $12 \mathrm{~h}$, a macroplasmodium of diameter $1.5 \mathrm{~cm}$, growing on a $2.1 \mathrm{~cm}$ filter paper disc, was placed in a Warburg flask containing 8 to $9 \mathrm{ml}$ fresh growth medium so that the filter paper rested on the surface of the medium and was supported by the centre well. Carbon dioxide was absorbed by $0.4 \mathrm{ml} 10 \%(\mathrm{w} / \mathrm{v}) \mathrm{KOH}$ placed in the side-arm with a strip of filter paper. Mechanical shaking was not used and $\mathrm{O}_{2}$ uptake was followed at intervals. At least five manometer readings were taken during a 20 to $40 \mathrm{~min}$ period to determine the rate of $\mathrm{O}_{2}$ uptake at each time. Flask and manometer taps were left open between each set of readings. The time of mitosis (telophase) was estimated by phasecontrast microscopical examination of $95 \%$ (v/v) aqueous ethanol-fixed smears (Guttes et al., 1961) from sister macroplasmodia inoculated simultaneously and growing at $26^{\circ} \mathrm{C}$ in an incubator. When it was possible to estimate mitotic times directly from the culture at the end of the experiment, these were found to be unaffected by conditions in the Warburg flask.

Preparation of homogenates for enzyme assay. A section of a surface culture, with the central inoculum spot omitted, was washed with ice-cold $50 \mathrm{~mm}$-Tris/ $\mathrm{HCl}$ buffer $\mathrm{pH} 7 \cdot 5$, frozen on solid $\mathrm{CO}_{2}$ in 1 to $3 \mathrm{ml}$ of this buffer containing $25 \%(\mathrm{w} / \mathrm{v})$ glycerol and stored at $-20^{\circ} \mathrm{C}$ overnight. Immediately after thawing, the plasmodium was treated ultrasonically for 3 to $5 \mathrm{~s}$ (MSE $150 \mathrm{~W}$ Ultrasonic Disintegrator, $3 \mathrm{~mm}$ diam. Ti probe, $6.5 \mu \mathrm{m}$ amplitude, frequency approx. $20 \mathrm{kHz}$ ) in a glass tube cooled by an ice/water mixture. An additional $45 \mathrm{~s}$ ultrasonic treatment was used to release latent cytochrome oxidase activity. The crude homogenate was used for enzyme assay.

Enzyme assays. The assay for fumarase (EC 4.2.1.2) was based on that of Racker (1950). The reaction mixture contained, in a final volume of $3 \mathrm{ml}: 150 \mu \mathrm{mol} \mathrm{L}$-malate, $100 \mu \mathrm{mol}$ potassium phosphate buffer pH 7.4 and 20 to $100 \mu \mathrm{l}$ enzyme extract. The rate of fumarate production was followed at $250 \mathrm{~nm}$ and $30^{\circ} \mathrm{C}$ and increased linearly with the amount of enzyme for rates of $\Delta A_{250}$ up to at least $5.5 \times 10^{-2} \mathrm{~min}^{-1}$.

Succinate dehydrogenase (EC 1.3.99.1) activity was measured according to Breidenbach et al. (1967). The assay mixture contained, in a final volume of $3 \mathrm{ml}: 120 \mu \mathrm{mol}$ sodium succinate, $0.65 \mu \mathrm{g}$ phenazine methosulphate, $0.18 \mathrm{mg}$ 2,6-dichlorophenolindophenol, $30 \mu \mathrm{mol} \mathrm{KCN}, 340 \mu \mathrm{mol}$ Tris/HCl buffer $\mathrm{pH} 7.5$ and 20 to $100 \mu$ l enzyme extract. The enzyme activity could be increased as much as threefold by incubating the extract at succinate concentrations above $50 \mathrm{mM}$, so each sample was routinely 'substrate activated' (Singer et al., 1973) for $15 \mathrm{~min}$ immediately before adding phenazine methosulphate to start the reaction. The rate of dye reduction at $30^{\circ} \mathrm{C}$ was measured at $600 \mathrm{~nm}$ against that in control reaction mixtures lacking succinate. The rate increased linearly with the amount of enzyme extract for rates of $-\Delta A_{600}$ up to at least $4.4 \times 10^{-2} \mathrm{~min}^{-1}$.

Malate dehydrogenase (EC 1.1.1.37) activity was assayed by following the reduction of NAD with L-malate as substrate, according to the method of Teague \& Henney (1973).

Cytochrome oxidase (EC 1.9.3.1) activity was estimated by following the reduction of cytochrome $c$ at $550 \mathrm{~nm}$ and $30^{\circ} \mathrm{C}$ (Smith, 1961). The assay mixture contained, in a final volume of $3 \mathrm{ml}: 150 \mu \mathrm{mol}$ potassium phosphate buffer $\mathrm{pH} 7 \cdot 3,120 \mathrm{nmol}$ cytochrome $c$ and 20 to $100 \mu \mathrm{l}$ enzyme extract. Before use the cytochrome $c$ was reduced with dithionite and the excess dithionite was oxidized by aeration. High concentrations of cytochrome $c$ inhibit cytochrome oxidase activity and the concentration used was the highest at which Michaelis-Menten kinetics were followed. Consequently, when the rate of $-\Delta A_{550}$ was less than $1.5 \times 10^{-2}$ 
$\min ^{-1}$ (and the rate of substrate consumption therefore below $2 \% \mathrm{~min}^{-1}$ ), the reaction approximated at first to zero order and the initial linear rate was measured.

Enzyme activities are expressed as $\mu \mathrm{mol}$ substrate converted $\min ^{-1}$ (mg protein) ${ }^{-1}$.

Protein estimation. The protein in two samples of each homogenate was precipitated with an equal volume of $8 \%(\mathrm{w} / \mathrm{v})$ trichloroacetic acid and washed twice in $4 \%(\mathrm{w} / \mathrm{v})$ trichloroacetic acid. The pellets were solubilized in $0.4 \mathrm{M}-\mathrm{NaOH}$ at $45^{\circ} \mathrm{C}$ for $60 \mathrm{~min}$ and assayed in duplicate by the method of Lowry using bovine serum albumin as standard.

\section{RESULTS}

Respiration during the mitotic cycle

The respiration rate of a single macroplasmodium of Physarum polycephalum increased discontinuously in two steps during the synchronous mitotic cycle (Fig. 1). Two curves are shown, one for a culture which had been subjected to an initial period of starvation at the time of inoculation, the other for a culture inoculated simultaneously but supplied immediately with growth medium. Depriving the culture of medium for a short period is a routine step for obtaining thin, rapidly growing plasmodia, but it is not essential for the preparation of a synchronous culture. The third and fourth mitoses in the culture fed immediately after inoculation preceded those in the second culture by approximately the length of the starvation period. No difference, however, was observed between the two plasmodia in the degree of synchrony or in the pattern of respiration. In each case interruptions to the increase in respiration rate occurred twice per mitotic cycle: once at about the time of mitosis and once in mid-interphase.

To determine whether these fluctuations in the pattern of respiration decay with time after inoculation, or if they are sustained even after long periods of synchronous growth, we cultured small macroplasmodia on filter paper for $4 \mathrm{~d}$ (approximately 10 to 12 synchronous mitotic cycles). The pattern of $\mathrm{O}_{2}$ uptake during the mitotic cycles of two such cultures is shown in Fig. 2. In both cultures a plateau in the rate of respiration coincided approximately with the estimated time of mitosis; in one (upper curve) a mid-interphase plateau is also clearly apparent.

The extent of the increase in respiration rate between mitoses in Fig. 2 (1.97 and 1.82 for the upper and lower curves, respectively) suggests that growth in these cultures was more balanced than in those shown in Fig. 1, where the rate in each increased only 1.75 -fold between the third and fourth mitoses. This may indicate that more than 4 mitotic cycles were required before the macroplasmodial cultures recovered from the effects of the inoculation procedures. Despite this, however, the pattern of respiration was virtually unchanged over 6 to 8 mitotic cycles (cf. Figs 1 and 2). Thus it is unlikely that the same perturbations which led to temporarily unbalanced growth could account for the discontinuities in the respiratory pdttern.

The results from a number of separate experiments in which respiration rate was followed in single macroplasmodia are summarized in Fig. 3. The mean times for the mid-points of the two plateaux in the respiratory pattern, expressed as a proportion of the mitotic cycle (with standard deviations), were $0.40 \pm 0.095(6)$ and $0.94 \pm 0.044(10)$; the mean values for the duration of the plateaux were $0.22 \pm 0.011$ (6) and $0.22 \pm 0.079$ (10) cycles, respectively. A decrease in the rate of $\mathrm{O}_{2}$ uptake (varying between 4 and $17 \%$ ) was frequently detected towards the end of the second plateau, at or close to the time of mitosis (e.g. Figs 1 and 2), but no similar decrease was ever observed in mid-interphase.

\section{Respiration during spherule germination}

Spherules are the vegetative resting stage of the $P$. polycephalum plasmodium. If they are washed free of slime and allowed to germinate on filter paper in close proximity to one another, as described in Methods, they do so with a high degree of synchrony. Following germination they quickly fuse to form a single macroplasmodium which undergoes a normal 


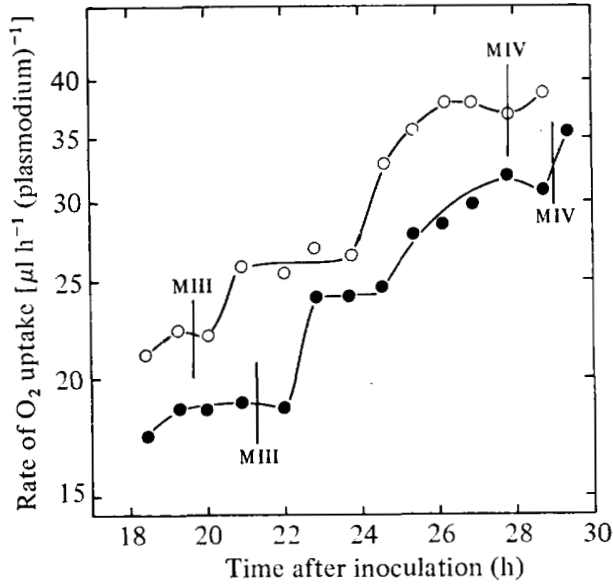

Fig. 1

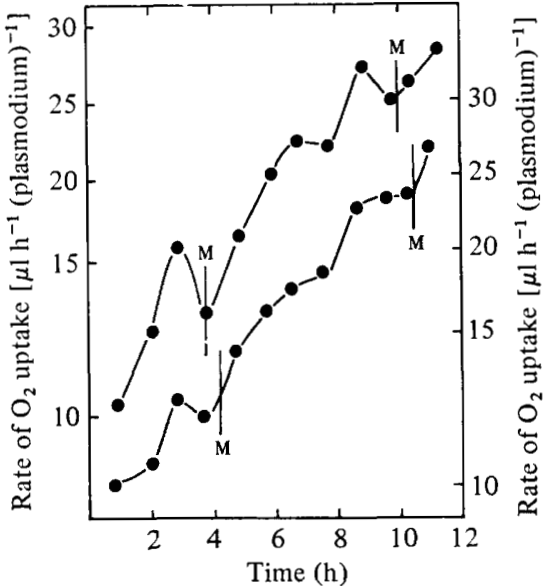

Fig. 2

Fig. 1. Oxygen uptake by single macroplasmodia of Physarum polycephalum during the synchronous mitotic cycle. Two plasmodial cultures were inoculated simultaneously on to filter paper as described in Methods; growth medium was supplied to one immediately $(O)$ and to the other after an interval of $85 \mathrm{~min}(\mathrm{O})$. Shortly before the third synchronous mitosis the macroplasmodia, still resting on their filter paper discs, were transferred intact to Warburg flasks and $\mathrm{O}_{2}$ uptake was monitored at $26^{\circ} \mathrm{C}$ for approx. 1.5 mitotic cycles $(12 \mathrm{~h})$ as described in Methods. MIII and MIV indicate the approximate times of the third and fourth mitoses, estimated using sister macroplasmodia growing in an incubator at the same temperature.

Fig. 2. Pattern of $\mathrm{O}_{2}$ uptake by single macroplasmodia after a prolonged period of synchronous growth. Duplicate macroplasmodia were cultured on filter paper as for Fig. 1, except that inoculation was made with single microplasmodia rather than a concentrated suspension. Growth was allowed to continue for $4 \mathrm{~d}$ (more than 10 mitotic cycles) after which macroplasmodia were transferred intact to Warburg flasks for measurement of respiration rate as in Fig. 1. $M$ indicates the approximate times of mitosis, estimated from smears taken before and after the experimental period. The upper curve corresponds to the left-hand ordinate scale and the lower curve to the right-hand scale.

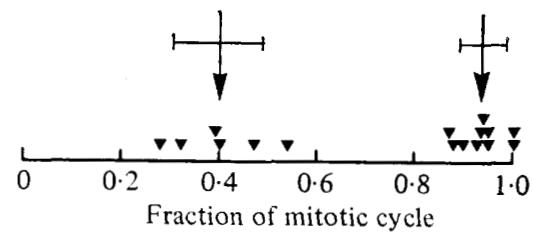

Fig. 3. Timing of plateaux in the pattern of $\mathrm{O}_{2}$ uptake with respect to the mitotic cycle. Each triangle represents the mid-point of a period in which the respiration rate of a single macroplasmodium was observed to plateau. The duration of the mitotic cycle is taken as $1 \cdot 0$. The mean and standard deviation for each of the two groups of points are indicated by an arrow and crossbar.

synchronous mitosis approximately $9 \mathrm{~h}$ later. This system not only permitted us to study respiration during the transition from the quiescent state to the rapidly growing plasmodium, but also enabled us to compare the pattern of respiration during the first mitosis with that in a normal synchronous culture.

The spherules were already respiring within 45 min of replacing stale medium with diluted growth medium, and the rate of $\mathrm{O}_{2}$ uptake increased continuously throughout the $8 \mathrm{~h}$ germination period (Fig. 4). After outgrowth had begun, however, the increase in respiration rate changed to a discontinuous pattern remarkably similar to that seen during the normal mitotic cycle (Figs 1 and 2). This pattern is evident in both cultures monitored after germination. One of these had been transferred to full-strength growth medium immediately after outgrowth began, while the other was transferred to fresh diluted medium at this time. 


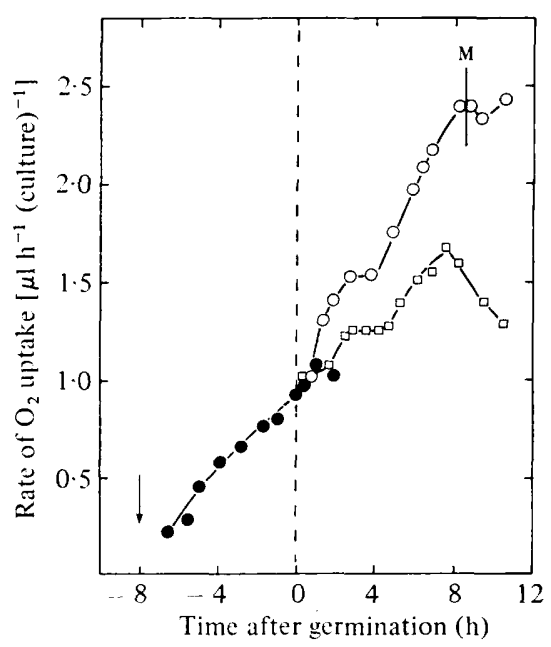

Fig. 4. Oxygen uptake during spherule germination. Cultures of synchronously germinating spherules were prepared as described in Methods. Immediately after washing and inoculating the spherules on to filter paper (at the time indicated by an arrow) one culture was transferred to a Warburg flask and $\mathrm{O}_{2}$ uptake was monitored for the period up to and including the initial stages of outgrowth (O); after outgrowth had begun, two further cultures were transferred to Warburg flasks containing either fresh one-third strength growth medium $(\square)$ or fresh undiluted growth medium $(\mathrm{O})$ and $\mathrm{O}_{2}$ uptake was measured until after the first synchronous mitosis (M).

In the latter culture an interphase plateau lasting 120 min was observed, compared to only $60 \mathrm{~min}$ in the former culture where the overall rate of increase was greater and the synchrony of germination less good. The gradual decrease in the rate of $\mathrm{O}_{\Sigma}$ uptake towards the end of the experiment in the culture growing on diluted growth medium was probably due to exhaustion of the medium. In the other culture, where the full-strength medium supported continued growth, a further plateau was recorded at about the time of the first mitosis. Thus the pattern of respiration was almost identical to that in the normal plasmodium.

\section{Mitochondrial enzyme activities during the mitotic cycle}

No marked oscillations were detected in the specific activities of succinate dehydrogenase, fumarase or malate dehydrogenase (Fig. 5). (The significance of a small decrease in the specific activities of each of these three enzymes at or around the time of each mitosis is not certain.) In contrast, two peaks in cytochrome oxidase activity were seen at 0.3 and 0.9 of the cycle (Fig. 5). The same oscillatory pattern of cytochrome oxidase activity was observed in a number of separate experiments. In one such experiment (Fig. 6) samples were assayed for both cytochrome oxidase and respiratory activity and the rate of $\mathrm{O}_{2}$ uptake (expressed here on a total protein basis) also fluctuated in a biphasic manner, with maxima coinciding with those in cytochrome oxidase activity at 0.2 and 0.7 of the cycle. This result was obtained by taking samples at intervals from large macroplasmodia ( 5 to $7 \mathrm{~cm}$ diam.) and monitoring them briefly for respiration rate, rather than by growing small macroplasmodia $(1.5 \mathrm{~cm}$ diam.) continuously in the Warburg flask as for Figs 1 and 2 . The close agreement between the results obtained by the different experimental procedures can be seen when the data are expressed on a plasmodial basis (Fig. 6). Conversion of the data to this form was made on the assumption that the protein content of these cultures increased exponentially, although a similar result would have been obtained if, for example, the pattern of protein accumulation reported by Birch \& Turnock (1977) had been used instead as the basis for our calculations. 


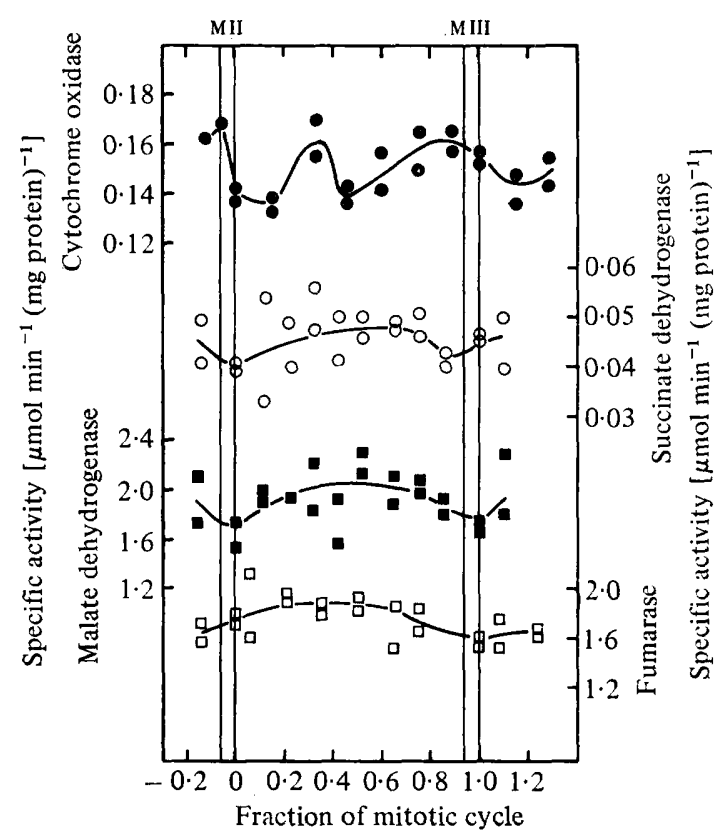

Fig. 5. Mitochondrial enzyme activities during the synchronous mitotic cycle. Segments of macroplasmodial cultures were taken at intervals during synchronous growth and homogenates were assayed for cytochrome oxidase $(\bullet)$, succinate dehydrogenase $(O)$, malate dehydrogenase $(\boldsymbol{D})$ and fumarase $(\square)$ activities as described in Methods. Normally two samples were taken simultaneously from sister cultures; each experimental point represents the average of duplicate enzyme assays performed on each sample. MII and MIII indicate the periods of mitosis, from prophase to telophase.

\section{DISCUSSION}

The persistence of the stepped pattern of respiration into at least the tenth mitotic cycle after inoculation (Fig. 2), and the demonstration that the same pattern could be seen under several conditions of culture (Figs 1,4 and 6), indicates that it is a normal feature of synchronous macroplasmodial growth in $P$. polycephalum.

Robbins \& Morrill (1969) have suggested that respiratory activity in the cell cycle reflects the changing demands of macromolecular synthesis, and this hypothesis is supported by the frequent correlation, in a variety of cell types, between a fall in the rate of $\mathrm{O}_{2}$ uptake and the cessation of RNA synthesis at the time of mitosis (reviewed by Mitchison, 1971). A biphasic pattern of RNA and protein synthesis in $P$. polycephalum, which closely resembles the pattern of specific respiration rate, has been reported on the basis of pulse-labelling studies with radioactive uridine (Mittermayer et al., 1964) and lysine (Mittermayer et al., 1966). A criticism of such studies, however, is that the rate of labelled precursor incorporation is influenced by factors other than the rate of macromolecular synthesis, notably by changes in the size of the endogenous precursor pool. It may therefore be significant that Fink (1975) has reported fluctuations in the UTP pool in synchronously growing $P$. polycephalum which might account for the pattern of uridine incorporation observed by Mittermayer et al. (1964). Evidence obtained by other techniques indicates that, apart from a brief stoppage during mitosis itself, the rate of synthesis of RNA (Nygaard et al., 1960; Hall \& Turnock, 1976) and of protein (Mittermayer et al., 1966; Brewer, 1972; Birch \& Turnock, 1977 ) increases continuously between one mitosis and the next. An alternative explanation may therefore have to be found for the pattern of respiration in $P$. polycephalum.

One possibility is that oscillations in a complex feedback control system are responsible for the respiratory pattern (Poole et al., 1973). Low frequency oscillations in the respiration 


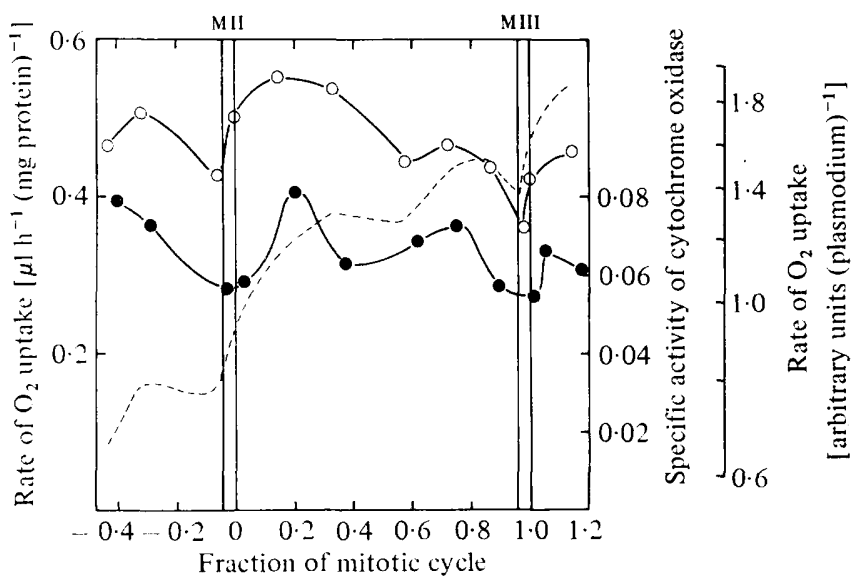

Fig. 6. Cytochrome oxidase activity and $\mathrm{O}_{2}$ uptake in the synchronous mitotic cycle. Oxygen uptake and cytochrome oxidase activity were measured at intervals in samples from a large $(5$ to $7 \mathrm{~cm}$ diam.) macroplasmodium. A 90 to $120^{\circ}$ segment, from which the inner inoculum spot had been removed, was carefully teased off the filter paper and submerged in $2.0 \mathrm{ml}$ fresh growth medium in a Warburg flask. The centre well contained $0.35 \mathrm{ml} 10 \%(\mathrm{w} / \mathrm{v}) \mathrm{KOH}$ and a filter paper strip to absorb $\mathrm{CO}_{2}$. Oxygen uptake was followed manometrically for 20 to $25 \mathrm{~min}$ with shaking at 100 strokes $\mathrm{min}^{-1}$. The rate of $\mathrm{O}_{2}$ uptake by any sample did not exceed $1.8 \mu \mathrm{l} \mathrm{min}{ }^{-1}$. The samples used in manometric measurements were also used, after homogenization, for the assay of cytochrome oxidase activity; this is expressed as $\mu \mathrm{mol}$ cytochrome $c$ oxidized $\mathrm{min}^{-1}$ (mg protein) ${ }^{-1}$. The rate of oxygen uptake is expressed both per mg protein $(O)$ and, to aid comparison with Figs 1 and 2, on a plasmodial basis $(--)$ in arbitrary units. The latter curve was obtained by recalculating the manometric data on the assumption that the protein content of the plasmodium increased twofold in an exponential manner between successive mitoses. The periods of mitosis (MII and MIII) were accurately determined by examination of smears taken from both the macroplasmodial cultures and from the samples themselves before and after the brief period of manometric measurements.

rate of Escherichia coli and Candida utilis can be induced, in the absence of synchronous cell division, by changes in the conditions of culture (Poole, 1977). In P. polycephalum, the sharp drop in the ATP concentration at mitosis (Chin \& Bernstein, 1968; Sachsenmaier et al., 1969; Bersier \& Braun, 1974; Fink, 1975) and the consequent decrease in adenylate charge from 0.74 to 0.46 (calculated from the data of Sachsenmaier et al., 1969) might be the trigger for the observed respiratory oscillations. The persistence of the pattern for many mitotic cycles after inoculation (Fig. 2) could then be explained by the recurrence of the same perturbation at each synchronous mitosis.

Changes in the rate of protoplasmic streaming might account for both the depletion of the ATP pool and the frequently observed decrease in the rate of respiration close to the time of mitosis (Figs 1, 2, 4 and 6). This would be the case if the shuttle streaming which is such a distinctive feature of this stage of the $P$. polycephalum life cycle has a role in facilitating gaseous exchange in the unusually large syncytium. The rate of $\mathrm{O}_{2}$ uptake would then be limited by diffusion during the $20 \mathrm{~min}$ period before telophase when streaming ceases (Sachsenmaier et al., 1973). From Fig. 6, where the experimental procedure allowed accurate timing of changes in respiratory activity relative to mitosis, it is evident that the respiration rate drops by up to $20 \%$ during the same $20 \mathrm{~min}$ period, and recovers at the start of the next mitotic cycle, just as streaming is reinitiated (Sachsenmaier et al., 1973). The sudden decrease in ATP concentration at mitosis is consistent with this idea, since it indicates that controls other than those which operate to maintain energy balance are responsible for the drop in the rate of respiration.

The specific activities of fumarase, succinate dehydrogenase and malate dehydrogenase remained relatively constant during the mitotic cycle (Fig. 5), indicating that their synthesis 
roughly parallels that of total protein. In this way they resemble the majority of those enzymes monitored in $P$. polycephalum which are not associated with nucleic acid metabolism (Sachsenmaier \& Ives, 1965; Hüttermann et al., 1970; Wolf et al., 1973). In the case of cytochrome oxidase, however, an oscillating pattern similar to that of respiratory activity was observed (Figs 5 and 6). This does not necessarily imply discontinuous synthesis of enzyme protein, since it has been shown that a stepped pattern of increase in cytochrome oxidase activity occurs in the cell cycle of $S$. cerevisiae despite a continuous accumulation of its structural counterpart, the cytochrome $a a_{3}$ complex (Cottrell et al., 1975).

While periodicity in the accumulation of respiratory enzymes, including cytochrome oxidase, has been reported in a number of synchronous micro-organisms, the pattern has not previously been found to coincide with that of $\mathrm{O}_{2}$ uptake (Cottrell \& Avers, 1970; Forde \& John, 1973; Poole \& Lloyd, 1974). It is therefore unlikely that fluctuations in the specific activity of the terminal oxidase can account for the respiratory oscillations observed here. In agreement with this it can be calculated that the minimum in vitro activity of cytochrome oxidase was sufficient to support a rate of $\mathrm{O}_{2}$ uptake of $0.64 \mu \mathrm{l} \mathrm{min} \mathrm{m}^{-1}$ (mg protein) ${ }^{-1}$, almost $20 \%$ faster than the maximum respiratory activity observed in the same experiment (Fig. 6). Assuming that the coincidence between the patterns of increase in cytochrome oxidase activity and respiration rate is not simply fortuitous, it is therefore likely that each is modulated in the mitotic cycle by the same, as yet unidentified, controls.

We are indebted to H. Harlass for excellent technical assistance and to Dr Joyce Mohberg, Professor J. M. Mitchison and Dr J. Creanor for helpful discussion. This work was carried out while B.G.F. was the recipient of a Royal Society European Exchange Fellowship, which is gratefully acknowledged.

\section{REFERENCES}

Barath, Z. \& KünTZEL, H. (1972). Cooperation of mitochondrial and nuclear genes specifying the mitochondrial genetic apparatus in Neurospora crassa. Proceedings of the National Academy of Sciences of the United States of America 69, 1371-1374.

Bersier, D. \& Braun, R. (1974). Pools of deoxyribonucleoside triphosphates in the mitotic cycle of Physarum. Biochimica et biophysica acta 340, 463-471.

BIRCH, B. \& Turnock, G. (1977). Synthesis of protein during the nuclear division cycle in Physarum polycephalum. FEBS Letters 84, 317319.

Braun, R. \& Evans, T. E. (1969). Replication of nuclear satellite and mitochondrial DNA in the mitotic cycle of Physarum polycephalum. Biochimica et biophysica acta 182, 511-522.

Breidenbach, R. W., Castelfranco, P. \& Criddle, R. S. (1967). Biogenesis of mitochondria in germinating peanut cotyledons. II. Changes in cytochromes and mitochondrial DNA. Plant Physiology 42, 1025-1041.

Brewer, E. N. (1972). Polysome profiles, amino acid incorporation in vitro, and polysome reaggregation following disaggregation by heat and shock in Physarum polycephalum. Biochimica et biophysica acta 277, 639-645.

Chin, B. \& Bernstein, I. A. (1968). Adenosine triphosphate and synchronous mitosis in Physarum polycephalum. Journal of Bacteriology 108, 10721086.
Cottrell, S. F. \& Avers, C. J. (1970). Evidence of mitochondrial synchrony in synchronous cell cultures of yeast. Biochemical and Biophysical Research Communications 38, 973-980.

Cottrell, S. F., Rabinowitz, M. \& Getz, G. S. (1975). Cytochrome synthesis in synchronous cultures of the yeast, Saccharomyces cerevisiae. Journal of Biological Chemistry 250, 4087-4094.

Daniel, J. W. \& Baldwin, H. H. (1964). Methods of culture for plasmodial myxomycetes. Methods in Cell Physiology 1, 9-41.

Dharmalingam, K. \& Jayaraman, J. (1973). Mitochondriogenesis in synchronous cultures of yeast. 1. Oscillatory pattern of respiration. Archives of Biochemistry and Biophysics 157, 197-202.

FINK, K. (1975). Fluctuations in the deoxy- and ribonucleoside triphosphate pools during the mitotic cycle of Physarum polycephalum. Biochimica et biophysica acta 414, 85-89.

Forde, B. G. \& John, P. C. L. (1973). Stepwise accumulation of autoregulated enzyme activities during the cell cycle of the eucaryote Chlorella. Experimental Cell Research 79, 127-135.

Greksák, M. \& Hanicová, M. (1973). Activities of succinate dehydrogenase and cytochrome oxidase in synchronous cultures of aerobically and anaerobically grown yeast. Biologica, Bratislava 28, 425-433.

Guttes, E., Guttes, S. \& Rusch, H. P. (1961). The morphology and development of Physarum polycephalum grown in pure culture. Devolopmental Biology 3, 588-614. 
Guttes, E., Guttes, S. \& Devi, V. R. (1969). Division stages of the mitochondria in normal and actinomycin D-treated plasmodia of Physarum polycephalum. Experientia 25, 66-68.

Hall, L. \& Turnock, G. (1976). Synthesis of ribosomal RNA during the mitotic cycle in the slime mould Physarum polycephalum. European Journal of Biochemistry 62, 471-477.

Hüt'termanN, A., Porter, M. T. \& Rusch, H. P. (1970). Activity of some enzymes in Physarum polycephalum. 1. In the growing plasmodium. Archiv für Mikrobiologie 74, 90-100.

Kuenzi, M. T. \& FieTcher, A. (1969). Changes in carbohydrate composition during the budding cycle of Saccharomyces cerevisiae. Archiv für Mikrobiologie 64, 396-407.

Lloyd, D., Turner, G., PoOle, R. K., Nicholl, W. G. \& RoACH, G. I. (1971). A hypothesis of nuclear-mitochondrial interactions based on experiments with Tetrahymena pyriformis. Subcellular Biochemistry 1, 91-95.

Mrtchison, J. M. (1971). The Biology of the Cell Cycle. Cambridge University Press.

Mrtchison, J. M. (1977). Enzyme synthesis during the cell cycle. In Cell Differentiation in Microorganisms, Plants and Animals, pp. 377-401. Edited by L. Nover \& K. Mothes. Jena: Fischer.

Mittermayer, C., Braun, R. \& RusCh, H. P. (1964). RNA synthesis in the mitotic cycle of Physarum polycephalum. Biochimica et biophysica acta 91, 399-405.

Mittermayer, C., Braun, R., Chayka, T. C. \& RusCH, H. P. (1966). Polysome patterns and protein synthesis during the mitotic cycle of Physarum polycephalum. Nature, London 210, 1133-1137.

Nosoh, Y. \& TakamiYa, A. (1962). Synchronisation of the budding cycle in yeast cells, and the effect of carbon monoxide and nitrogen deficiency on the synchrony. Plant and Cell Physiology 3, 53-66.

NygaARD, O. F., GutTes, S. \& Rusch, H. P. (1960). Nucleic acid metabolism in a slime mould with synchronous mitosis. Biochimica et biophysica acta 38, 298-306.

Poole, R. K. (1977). The influence of growth substrate and capacity for oxidative phosphorylation on respiratory oscillations in synchronous cultures of Escherichia coli K12. Journal of General Microbiology 99, 369-377.

Poole, R. K. \& Lloyd, D. (1974). Changes in respiratory activities during the cell cycle of the fission yeast Schizosaccharomyces pombe $972 \mathrm{~h}^{-}$ growing in the presence of glycerol. Biochemical Journal 144, 141-148.

Poole, R. K., Lloyd, D. \& Kemp, R. B. (1973). Respiratory oscillations and heat evolution in synchronously dividing cultures of the fission yeast Schizosaccharomyces pombe $972 \mathrm{~h}^{-}$. Journal of General Microbiology 77, 209-220.

RACKER, E. (1950). Spectrophotometric measurement of fumaric and cis-aconitic acids. Biochimica et biophysica acta 4, 211-214.

Robbins, E. \& Morrill, G. A. (1969). Oxygen uptake during the HeLa cell life cycle and its correlation with macromolecular synthesis. Journal of Cell Biology 43, 629-633.

SACHSENMAIER, W. (1964). Zur DNS- und RNSsynthese in Teilungszyklus synchroner Plasmodien von Physarum polycephalum. Biochemische Zeitschrift 340, 541-547.

SaChsenmaier, W. \& Ives, D. H. (1965). Periodische Änderungen der Thymidinkinase Activität in synchronen Mitosecyclus von Physarum polycephalum. Biochemische Zeitschrift 343, 399-406.

SaChSENMAIER, W., IMMich, H., Grunst, J., Scholz, R. \& BüCHER, TH. (1969). Free ribonucleotides of Physarum polycephalum. European Journal of Biochemistry 8, 557-561.

Sachsenmaier, W., Blessing, J., Brauser, B. \& HANSEN, K. (1973). Protoplasmic streaming in Physarum polycephalum: observations of spontaneous and induced changes of the oscillatory pattern by photometric and fluorometric techniques. Protoplasma 77, 381-396.

Schatz, G. \& Mason, T. (1974). The biosynthesis of mitochondrial proteins. Annual Review of Biochemistry 43, 51-87.

Scopes, A. W. \& Williamson, D. H. (1964). The growth and oxygen uptake of synchronously dividing cultures of yeast. Biochemical and Biophysical Research Communications 38, 750-757. Singer, T. P., Kearney, E. B. \& KenNey, W. C. (1973). Succinate dehydrogenase. Advances in Enzymology 37, 189-272.

SмITH, L. (1955). Spectrophotometric assay of cytochrome oxidase. Methods of Biochemical Analysis 2, 427-434.

Teague, W. M. \& Henney, H. R., JR (1973). Purification and properties of cytoplasmic and mitochondrial malate dehydrogenases of Physarum polycephalum. Journal of Bacteriology 116, 673684.

Wiemken, A., Matile, P. \& Moor, H. (1970). Vacuolar dynamics in synchronously budding yeast. Archiv für Mikrobiologie 70, 89-103.

Wolf, H., Finkenstedt, G., Woertz, G. \& SACHSENMAIER, W. (1973). Regulation von Nucleosidphosphorylierenden Enzymen im synchronen Mitose-zyklus von Physarumpolycephalum. HoppeSeyler's Zeitschrift für physiologische Chemie 354, 1260. 